\section{FRI0453 DOES DISCORDANCE BETWEEN BASELINE PATIENT'S AND EVALUATOR'S GLOBAL ASSESSMENT OF DISEASE ACTIVITY IMPACT RETENTION AND REMISSION RATES OF TNF INHIBITORS IN PATIENTS WITH PSORIATIC ARTHRITIS? DATA FROM THE EUROSPA RESEARCH COLLABORATION}

Brigitte Michelsen, Lykke Ørnbjerg, Heřman Mann, Joseph Sexton, Michael Nissen, Maria Jose Santos, Dan Nordström, Lennart T.H. Jacobsson, Ziga Rotar, Björn Gudbjornsson, Süleyman Serdar Koca, Catalin Codreanu, Manuel Pombo-Suarez, Irene van der Horst-Bruinsma, Anne Gitte Loft, Karel Pavelka, Eirik Kristianslund, Burkhard Moeller, Elsa Vieira-Sousa, AnnaMari Hokkanen, Ulf Lindström, Matija Tomsic, Thorvardur Jon Love, Berna Goker, Ruxandra Ionescu, Carlos Sánchez-Piedra, Marleen van de Sande, Gary Macfarlane, Florenzo lannone, Lise Hyldstrup, Niels Steen Krogh, Mikkel Ǿstergaard, Merete L. Hetland. EuroSpA Research Collaboration, on behalf of DANBIO (Denmark), ARTIS (Sweden), SCQM (Switzerland), NOR-DMARD (Norway), ATTRA (Czech Republic), Reuma.pt (Portugal), BIOBADASER (Spain), ROB-FIN (Finland), biorx.si (Slovenia), ICEBIO (Iceland), TURKBIO (Turkey), RRBR (Romania), ARC (Netherlands), BSRBR-AS (UK), GISEA (Italy), Denmark

Background: Discordance between baseline patient's and evaluator's global assessment of disease activity is common ${ }^{1}$ and may reduce the likelihood of remission following tumor necrosis factor inhibitor (TNFi) treatment in patients with psoriatic arthritis (PsA). ${ }^{2}$ However, the impact of such discordance on retention rates of TNFi in PsA patients remains unexplored.

Objectives: To explore the impact of discordance, defined as patient's minus evaluator's global assessment $(\triangle P E G)$, on retention rates and remission rates (DAS28(3)CRP (which does not include patient's global) and DAS28(4)CRP (which includes patient's global)) in PsA patients initiating their first TNFi treatment. We used pooled data from the European Spondyloarthritis Research Collaboration (EuroSpA).

Methods: TNFi naïve PsA patients from 11 European registries in Euro$\mathrm{SpA}$ were included. Kaplan-Meier analyses were used to estimate TNFi retention rates after 6/12/24 months, with comparison between baseline $\triangle P E G$ quartiles using the log rank test, stratified by gender. Remission rates were compared between different $\triangle P E G$ quartiles with Chi-square test, stratified by gender.

Results: A total of 5422 PsA patients were included. Mean (SD) age for women $(\mathrm{n}=2988) / \mathrm{men}(\mathrm{n}=2867)$ were $49.3(12.5) / 47.4(11.7) \quad$ years, disease duration $6.6(7.3) / 6.7(7.2)$ years, median(25-75 percentiles) baseline $\triangle P E G$ 17(0-38)/10(0-30) mm. Retention rates and DAS28(4)CRP but not DAS28 (3)CRP remission rates were lower for higher quartiles of baseline $\triangle P E G$ (table, figure).

Conclusion: High baseline discordance $(\triangle \mathrm{PEG})$ was associated with lower TNFi retention rates and with DAS28(4)CRP but not DAS28(3)CRP remission rates after 6, 12 and 24 months' follow-up in both male and female PsA patients. The choice of remission criteria in the follow-up of PsA patients may affect important treatment decisions, and may be of particular impact in patients with high baseline $\triangle P E G$.

\section{REFERENCES :}

[1] Lindstrom, et al., J Rheumatol 2015;42:1781-5; 2 Michelsen, et al. Ann Rheum Dis 2016;76:708-11.

Acknowledgement: Novartis Pharma $A G$ and IQVIA for supporting the EuroSpA collaboration.:

Disclosure of Interests: Brigitte Michelsen Grant/research support from: Unrestricted grant: Novartis, Consultant for: Novartis, UCB, Lykke Ørnbjerg Grant/research support from: Unrestricted grant: Novartis, Heřman Mann Consultant for: Pfizer, Eli Lilly, Sanofi, Speakers bureau: AbbVie, Roche, Pfizer, MSD, Eli Lilly, Sanofi, Joseph Sexton: None declared, Michael Nissen Consultant for: AbbVie, Lilly, Novartis, and Pfizer, Maria Jose Santos: None declared, Dan Nordström Grant/research support from: MSD, Pfizer, Consultant for: AbbVie, BMS, MSD, Novartis, Roche, Pfizer, UCB, Speakers bureau: Novartis, UCB, Lennart T.H. Jacobsson Consultant for: LJ has received lecture and consulting fees from Pfizer, Abbvie, Novartis, Eli-Lily and Janssen, Ziga Rotar: None declared, Björn Gudbjornsson: None declared, Süleyman Serdar Koca: None declared, Catalin Codreanu: None declared, Manuel Pombo-Suarez: None declared, Irene van der Horst-Bruinsma Grant/research support from: MSD, Pfizer, AbbVie, Consultant for: Abbvie, UCB, MSD, Novartis, Speakers bureau: BMS, AbbVie, Pfizer, MSD, Anne Gitte Loft: None declared, Karel Pavelka: None declared, Eirik kristianslund: None declared, Burkhard Moeller Consultant for: Swissmedic Human Medicines Expert Committee Member (regulatory agency), Elsa Vieira-Sousa Grant/research support from: MSD, Novartis, Anna-Mari Hokkanen: None declared, Ulf Lindström: None declared, Matija Tomsic: None declared, Thorvardur Jon Love Consultant for: Received reimbursment from Celgene for speaking about guidelines for the treatment of psoriatic arthritis, Berna Goker: None declared, Ruxandra lonescu: None declared, Carlos Sánchez-Piedra: None declared, Marleen van de Sande Grant/research support from: van Janssen, Novartis, Eli Lily, Consultant for: Novartis and Abbvie, Gary Macfarlane Grant/ research support from: Have received research grants (not current) from Abbvie and Pfizer.
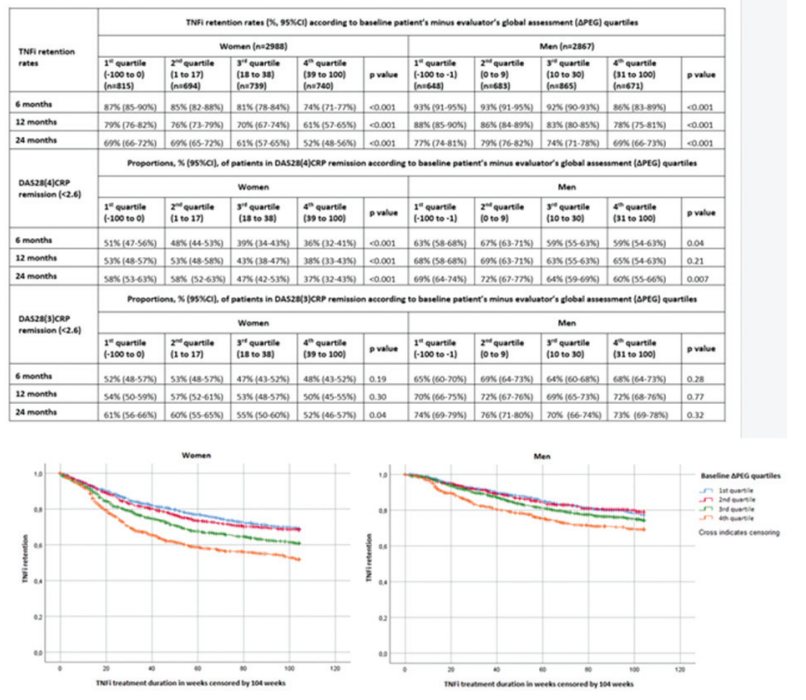

Have received research grants (not current) from the British Society for Rheumatology, who received the funds from Abbive, Pfizer and UCB. Have received research grant (current) from the British Society for Rheumatology, who received the funds from Celgene., Florenzo lannone: None declared, Lise Hyldstrup: None declared, Niels Steen Krogh: None declared, Mikkel Ǿstergaard Grant/research support from: Abbvie, Celgene, Centocor, Merck, Novartis, Consultant for: Abbvie, BMS, Boehringer-Ingelheim, Celgene, Eli Lilly, Hospira, Janssen, Merck, Novartis, Novo, Orion, Pfizer, Regeneron, Roche, and UCB, Speakers bureau: Abbvie, BMS, Boehringer-Ingelheim, Celgene, Eli Lilly, Hospira, Janssen, Merck, Novartis, Novo, Orion, Pfizer, Regeneron, Roche, and UCB, Merete L. Hetland Grant/research support from: BMS, MSD, AbbVie, Roche, Novartis, Biogen, Pfizer, Consultant for: Eli Lilly, Speakers bureau: Orion Pharma, Biogen, Pfizer, CellTrion, Merck, Samsung Bioepis DOI: 10.1136/annrheumdis-2019-eular.863

\section{FRI0454 EVOLUTION OF SUBCLINICAL ATEROSCLEROSIS IN PATIENTS WITH PSORIASTIC ARTHROPATHY}

L Montolio-Chiva ${ }^{1}$, M Robustillo-Villarino ${ }^{2}$, A Sendra-García ${ }^{13}$, Marta AguilarZamora $^{1}$, C Vergara-Dangond ${ }^{4}$, Ana V Orenes Vera ${ }^{1}$, I Vázquez-Gómez ${ }^{1}$, À Martínez-Ferrer ${ }^{1}$, Elia Valls-Pascual ${ }^{1}$, D Ybáñez-García $^{1}$, V Núñez-Monje $^{13}$, I Torner-Hernández ${ }^{1}$, Juanjo J. Alegre-Sancho ${ }^{1} .{ }^{1}$ Universitary Peset Doctor Hospital, Valencia, Spain, ${ }^{2}$ La Plana Hospital, Villarreal, Spain, ${ }^{3}$ Foundation for the promotion of sanitary and biomedical research in the Valencian Community (FISABIO), Valencia, Spain, ${ }^{4}$ HM Hospital, Madrid, Spain

Background: Patients with psoriatic arthritis (PsA) have a higher prevalence of classical vascular risk factors (CVRF) and early atherosclerosis determined by chronic inflammation.

Objectives: To study the evolution over time of different vascular damage evaluation measures in patients with PsA and investigate the factors related to these changes.

Methods: Pre-post longitudinal study with analytical components. PsA patients with peripheral joint involvement were included. Demographic (sex, age), clinical [duration of the disease, DAS28, current treatment, body mass index (BMI), CVRF, vascular events] and analytical variables [atherogenic index, glomerular filtration (GF-MDRD), fibrinogen, glycosylated hemoglobin (HbA1c), CRP, ESR, ultrasensitive CRP, Apolipoprotein A1, apolipoprotein B] were collected. Other variables were collected from the clinical history retrospectively. Basal vascular risk was estimated through SCORE tool. Extracranial carotid artery was explored with an Esaote MyLab70XVG ultrasound with linear probe $(7-12 \mathrm{mHz})$ and an 